\title{
PENGELOLAAN SARANA DAN PRASARANA DALAM MENINGKATKAN KUALITAS PEMBELAJARAN
}

\author{
Anis Khaerul Latifah1), Nadjematul Faizah2). \\ 1,2Institut Ilmu Al-Qur'an Jakarta \\ Email : khaerullanis@gmail.com ${ }^{1}$, nadjematulfaizah@iiq.ac.id ${ }^{2}$
}

\begin{abstract}
The purpose of this study was to determine the role of the Madrasah Head in managing educational facilities and infrastructure to improve the quality of learning, this study used a qualitative method. Sources of data in this study consisted of primary data and secondary data. Primary data were taken from interviews and documentation, interviews were conducted with 4 informants, namely the Head of Madrasah, Administrative Staff, Class IV Teachers and 2 Class IV students at MI MA'ARIF NU. The conclusion of this study shows that the head of the Madrasah has managerial competence, so that the Head of the MI MA'ARIF NU Madrasah plays a role in making and planning the procurement of facilities and infrastructure through meetings. In the use of facilities and infrastructure there are no written rules. Maintenance of facilities and infrastructure involves all madrasah residents in the maintenance and storage of facilities and infrastructure. Supervision of facilities and infrastructure is carried out by checking directly on the objects of infrastructure owned. The teacher's role in improving student achievement has gone well providing motivation in the learning process, using existing learning media and in accordance with the lesson plans resulting in an average academic achievement of 77 and non-academic students winning the competition so that they get an Accreditation $B$ score.
\end{abstract}

Keywords : management of infrastructure, the role of the principal, student achievement.

\section{Abstrak}

Tujuan dari penelitian ini adalah untuk mengetahui peran kepala madrasah dalam mengelola fasilitas pendidikan dan infrastruktur untuk meningkatkan kualitas pembelajaran, penelitian ini menggunakan metode kualitatif. Sumber data dalam penelitian ini terdiri dari data primer dan data sekunder. Data primer diambil dari wawancara dan dokumentasi, wawancara dilakukan dengan 4 informan, yaitu Kepala Madrasah, Staf Administrasi, Guru Kelas IV dan 2 siswa kelas IV di Mi Ma'arif NU. Kesimpulan dari penelitian ini menunjukkan bahwa kepala madrasah memiliki kompetensi manajerial, sehingga kepala Ma'arif NU Madrasah berperan dalam membuat dan merencanakan pengadaan fasilitas dan infrastruktur melalui pertemuan. Dalam penggunaan fasilitas dan infrastruktur, tidak ada aturan tertulis. Pemeliharaan fasilitas dan infrastruktur melibatkan semua warga madrasah dalam pemeliharaan dan penyimpanan fasilitas dan infrastruktur. Pengawasan fasilitas dan infrastruktur dilakukan dengan memeriksa langsung objek infrastruktur yang dimiliki. Peran guru dalam meningkatkan prestasi belajar siswa telah memberikan motivasi dalam proses pembelajaran, menggunakan media pembelajaran yang ada dan sesuai dengan rencana pelajaran yang menghasilkan prestasi akademik rata-rata 77 dan siswa nonakademik yang memenangkan kompetisi sehingga mereka mendapatkan akreditasi dengan grade B.

Kata kunci: Manajemen Sarana dan Prasarana, peran kepala Sekolah, prestasi siswa. 


\section{Pendahuluan}

Manajemen (pengelolaan) sarana dan prasarana menurut A.L Hartini adalah suatu aktivitas menyeluruh yang dimulai dari perencanaan, pengadaan, penggunaan, pemeliharaan dan penghapusan berbagai macam properti pendidikan yang dimiliki oleh suatu institusi Pendidikan (Hartini, 2011). Ayat yang menjelaskan Manajemen (Pengelolaan) yang termasuk dalam Q.S As-Sajdah ayat 5:

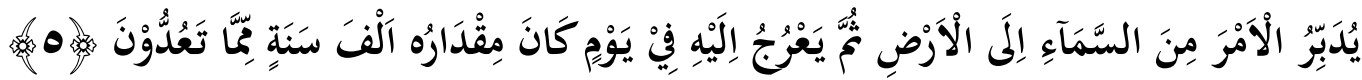

"Dia mengatur segala urusan dari langit ke bumi, kemudian (segala urusan) itu naik kepada-Nya pada hari yang kadarnya (lamanya) adalah seribu tahun menurut perhitunganmu". (QS. As-Sajdah [32]:5)

Berdasarkan firman Allah SWT tersebut dapat dipahami bahwa Allah swt adalah pengatur alam. karena manusia yang diciptakan Allah swt. Dapat diartikan bahwa manajemen maupun pengelolaan sarana dan prasarana dilakukan guna melayani seluruh masyarakat yang ada disekolah melalui sebuah usaha bersama untuk mencapai sebuah tujuan yang baik secara efektif dan efisien (Rahmat Hidayat, 2017).

Sebagaimana dalam pasal 45 ayat 1 Undang-undang Sistem Pendidikan Nasional No. 20 tahun 2003 bahwa: Setiap satuan pendidikan formal dan non formal menyediakan sarana dan prasarana yang memenuhi keperluan pendidikan sesuai dengan pertumbuhan dan perkembangan potensi fisik, kecerdasan intelektual, sosial, emosional, dan kejiwaan peserta didik.

Pentingnya sarana prasarana guna menunjang proses pendidikan, diatur oleh Undang-undang Republik Indonesia No. 20 Tahun 2003 tentang Sistem Pendidikan Nasional, BAB XII pasal 45: Setiap suatu pendidikan formal dan non formal menyediakan sarana dan prasarana yang memenuhi keperluan pendidikan sesuai dengan pertumbuhan dan perkembangan potensi fisik, kecerdasan intelektual, social, emosiona; dan kewajiban peserta didik. Ketentuan mengenai penyediaan sarana dan prasarana pendidikan pada semua satuan pendidikan sebagaimana dimaksud pada ayat (1).

Berdasarkan pengamatan yang sudah penulis lakukan di MI MA'ARIF NU Kertayasa terdapat sarana dan prasarana yang belum memadai baik dari lingkungan sekolah seperti kurangnya ketersediaan ruang kelas untuk siswa siswi MA'ARIF NU Kertayasa sehingga siswa maupun guru memanfaatkan sarana prasarana lain yaitu masjid yang berada di lingkungan sekolah tersebut selain itu, fasilitas lain seperti perpustakaan belum tersedia untuk para siswa, untuk tingkat SD/MI seharusnya sudah ada perpustakaan tetapi di MI MA'ARIF NU Kertayasa belum tersedia.

Sedangkan ketersediaan sarana seperti alat pelajaran dan alat peraga cenderung belum optimal mengenai pengaturan terhadap penggunaan dan 
pemeliharaan sarana tersebut. Sedangkan media pembelajaran seperti proyektor hanya terdapat diruang guru dan hanya digunakan oleh beberapa guru saja, karena tidak semua guru mengerti cara menggunakannya. Adapun mengenai tempat-tempat penyimpanan atau gudang untuk menyimpan fasilitas-fasilitas tersebut masih kurang dalam perawatannya, sehingga terjadi penumpukan barang bahkan ada barang yang tidak terpakai berada diluar gudang penyimpanan. Walaupun dengan keterbatasan sarana dan prasarana tersebut akan tetapi proses belajar mengajar tetap berjalan dengan semestinya dan prestasi siswa juga dapat dikatakan sangat baik. Dari hal ini dapat dilihat bahwa sarana dan prasarana memiliki peran penting dalam proses belajar mengajar.

Madrasah Ibtidaiyah (MI) MA'ARIF NU Kertayasa memiliki prestasi yang bagus dan mendapatkan nilai akreditasi B walaupun dengan sarana dan prasarana yang ada, sebagian masyarakat tetap menyekolahkan anaknya di MI walaupun merasa sarana prasana tidak sama dengan sekolah lain, sehingga menimbulkan rasa ingin tahu penulis bagaimana manajemen tata kelola sekolah yang dipimpin oleh Kepala Sekolah dengan keterbatasan sarana dan prasarana. Dari hasil pengamatan awal penulis mengidentifikasi masalah di MI adalah sebagai berikut.

Dari beberapa penelitian dalam tinjauan Pustaka (Lisyati Khairiyah, Media Parmana, Dwi Nika Sari, Rima Ismatur, Khoridatul Mu'syaroh) yang sudah dilakukan para peneliti sebelum penulis menunjukkan hasil bahwa usaha yang dilakukan sekolah dalam mengelola sarana dan prasarana dapat meningkatkan kualitas pembelajaran. Sehingga penulis tertarik untuk mencari jawaban pada persoalan di atas untuk meneliti tentang. "Pengelolaan Sarana dan Prasarana Pendidikan dalam Meningkatkan Kualitas Pembelajaran di MI MA'ARIF NU KERTAYASA". Adapun tujuan penelitian ini yaitu untuk mengetahui prestasi siswa kelas 4 dan peranan Kepala Madrasah dalam mengelola sarana dan prasarana di MI MA'ARIF NU Kertayasa.

\section{Metode Penelitian}

Jenis penelitian yang digunakan yaitu metode penelitian kualitatif. Tempat penelitian di Madrasah Ibtidaiyah MA'ARIF NU Kertayasa yang terletak di jl. Melati No.3 RT 07 RW 02 Kelurahan Kertayasa, Kecamatan Kramat, Tegal, Jawa Tengah. Sumber data utama yaitu Kepala Madrasah MI MA'ARIF NU Kertayasa, guru MI MA'ARIF NU Kertayasa, staf tata usaha MI MA'ARIF NU Kertayasa dan siswa MI MA'ARIF NU Kertayasa, kemudian data sekunder didapatkan dari dokumentasi pelaksanaan pembelajaran dan dokumentasi pengelolaan sarana dan prasarana, Teknik pengumpulan data yang digunakan oleh penulis dalam penelitian ini yaitu, observasi, wawancara, dan dokumentasi. Adapun tahap yang dilakukan peneliti dalam menganalisis data sebagai berikut: Pertama, mengumpulkan data-data yang berkaitan dengan penelitian dari pembahasan para ahli dan penelitian terdahulu yakni berupa buku, jurnal, maupun skripsi. Kedua, menggabungkan informasi yang telah didapatkan dari pengamatan di lapangan. 
Ketiga, menganalisis hasil data-data wawancara yang telah dilakukan dan diperkuat dengan teori, jurnal, observasi, dan dokumentasi.

\section{Hasil Dan Pembahasan}

Dalam pengelolaan sarana dan prasarana pendidikan Madrasah meliputi perencanaan, penggunaan, pemeliharaan, pengawasan dan hambatan dalam pengelolaan sarana dan prasarana pendidikan di MI MA'ARIF NU Kertayasa.

\section{Perencanaan Sarana dan Prasarana Pendidikan di MI MA'ARIF NU Kertayasa}

Perencanaan penting dilakukan agar sarana dan prasarana tidak salah arah atau terbuang percuma. Perencanaan sarana dan prasarana sekolah adalah pendataan kegiatan yang dilakukan pihak sekolah, yaitu pelaksanaan rapat perencanaan sarana dan prasarana Pendidikan. Berdasarkan hasil wawancara dengan Kepala Madrasah, pihak madrasah selalu merencanakan kebutuhan sarana dan prasarana dengan mengadakan rapat perencanaan terlebih dahulu. Hal ini sebagaimana hasil wawancara dengan bapak Ahmad Choiron selaku Kepala Madrasah di MI MA'ARIF NU Kertayasa:

"Ya, mba kami memiliki pertemuan perencanaan menjelang tahun ajaran, jadi ketika kami memiliki pertemuan kami semua merencanakan apa yang perlu kami lakukan dan apa yang kami butuhkan"

Perencanaan di MI MA'ARIF NU Kertayasa pertama-tama menentukan sarana dan prasarana pendidikan mana yang perlu diganti, kemudian sesuaikan dengan dana yang ada. Seluruh warga madrasah dilibatkan dalam menentukan kebutuhan sarana dan prasarana sebagai pihak yang memberikan saran dan masukan. Setelah mendapatkan kepastian dana dan kebutuhan untuk pengadaan sarana dan prasarana, sekolah membuat perencanaan untuk membentuk anggota pendidik yang akan terlibat. Hal ini diperkuat oleh pernyataan yang mengatakan perencanaan adalah proses pertama ketika hendak melakukan pekerjaan, baik dalam bentuk pemikiran maupun kerangka kerja agar tujuan yang hendak dicapai mendapat hasil (Irjus Indrawan, 2015).

\section{Penggunaan Sarana dan Prasarana Pendidikan di MI MA'ARIF NU Kertayasa}

Dalam penggunaan sarana dan prasarana MI MA'ARIF NU Kertayasa, seluruh warga madrasah yang menggunakan sarana dan prasarana tersebut bertanggung jawab atas penggunaan sarana dan prasarana madrasah tersebut. pengelolaan sarana dan prasarana diserahkan langsung kepada kepala madrasah sebagaimana dijelaskan oleh bapak Ahmad Choiron:

"Ketika barang yang kita beli sampai itu di serahkan ke saya langsung kemudian nanti diserahkan ke bagian tata usaha" 
Penggunaan saran dan prasarana madrasah yang ada harus dikelola dengan baik agar sarana dan prasarana tersebut tetap terjaga dengan aman. Uraian data di atas menjelaskan bahwa penggunaan sarana dan prasarana di MI MA'ARIF NU Kertayasa dikelola langsung oleh kepala madrasah. dapat disimpulkan bahwa pengelolaan sarana dan prasarana yang di lakukan kepala madrasah sesuai dengan peraturan Menteri Agama (PMA) Nomor 90 tahun 2013.

\section{Pemeliharaan Sarana dan Prasarana Pendidikan di MI MA'ARIF NU Kertayasa}

Kegiatan pemeliharaan sarana dan prasarana madrasah selalu dilakukan untuk memastikan sarana dan prasarana terpelihara dan digunakan dengan baik. Pemeliharaan sarana dan prasarana MI MA'ARIF NU dilakukan oleh kepala madrasah dengan partisipasi seluruh warga madrasah. Hal ini juga sesuai pendapat bapak Murtono selaku staf tata usaha:

\section{"Tentu saja, semua terlibat untuk memelihara sarana dan prasarana"}

Jika ada beberapa kerusakan sarana seperti meja dan kursi akan dilakukan perbaikan, tetapi dengan dana yang terbatas perbaikan dilakukan dengan seminimal mungkin. Hal ini senada dengan pendapat kepala madrasah:

"Ya kalau rusaknya tidak terlalu parah terus masih bisa diperbaiki yah diperbaiki sama pak mur tapi kalau rusaknya parah diperbaiki sama tukang"

Selama melakukan perawatan tidak terlepas dari yang Namanya penyimpanan. Penyimpanan adalah salah satu kegiatan penyimpanan barang baik buku, ATK, maupun barang lainnya, baik baru maupun yang rusak. Demikian disampaikan staf tata usaha tentang penyimpanan sarana dan prasarana. Beliau menjelaskan:

"Penyimpanan nya di ruang guru soalnya kan tidak ada gudang, kalau rusaknya parah yah dihapus"

Kegiatan pemeliharaan sarana dan prasarana melibatkan seluruh warga madrasah. Bentuk pemeliharaan berupa penyimpanan dan perawatan yang sesuai, kepala madrasah sangat berperan penting dalam pelaksanaan proses penyimpanan sarana dan prasarana serta menjaga keamanan sarana dan prasarana tersebut. Kepala madrasah berperan dalam memelihara sarana dan prasarana dengan melakukan pengawasan terhadap fasilitas yang dimiliki madrasah. Dalam pemeliharaan sarana dan prasarana kepala madrasah juga memberikan bimbingan dan arahan kepada seluruh warga madrasah yang terlihat dalam pemeliharaan sarana dan prasarana yang dimilikinya.

Sarana dan prasarana madrasah merupakan barang yang perlu dijaga dan dirawat agar dapat berfungsi dalam proses pembelajaran. Di perkuat oleh pernyataan yang mengatakan pemeliharaan sarana dan prasarana pendidikan adalah kegiatan yang bertujuan untuk menegakan pengelolaan dan pengaturan 
agar semua sarana dan prasarana selalu dalam keadaan baik dan dapat digunakan secara efetif untuk mencapai tujuan Pendidikan (Sri Minarti, 2012).

\section{Pengawasan Sarana dan Prasarana Pendidikan di MI MA'ARIF NU Kertayasa}

Bentuk pengawasan sarana dan prasarana yang dilakukan oleh kepala madrasah MI MA'ARIF NU yaitu dengan melihat langsung perencanaan, pengadaan sampai dengan pemeliharaan. Pengawasan terhadap penggunaan dan pemeliharaan sarana dan prasarana juga dilakukan oleh kepala madrasah dan pengawasan dilakukan dengan cara pengecekan. Hal ini sesuai dengan pernyataan kepala madrasah:

\section{"Saya yang mengawasi langsung"}

Berdasarkan hasil wawancara di atas menyatakan bahwa kepala madrasah mengawasi langsung terhadap pemeliharaan sarana dan prasarana. Hal ini juga dibuktikan dengan adanya pengontrolan terhadap kondisi sarana dan prasarana. Pengontrolan tersebut dimulai dari perencanaa, penggunaan hingga pemeliharaan atau perawatan terhadap sarana dan prasarana milik madrasah. Pengawasan sarana dan prasarana dilakukan langsung oleh kepala madrasah tentang kondisi sarana dan prasarana, ajakan untuk mengawasi dan memelihara sarana dan prasarana yang dilakukan oleh kepala madrasah pada saat rapat guru ataupun pada saat memberikan pengarahan. Hal ini diperkuat oleh pernyataan yang mengatakan bahwa pengawasan adalah upaya untuk memastikan bahwa program dijalankan sesuai dengan rencana untuk mencapai tujuannya (Barnawi dan Arifin, 2012).

Hasil pembahasan diatas dapat disimpulkan bahwa peran manajerial kepala madrasah MI MA'ARIF NU berperan untuk membuat dan menyusun perencanaan pengadaan sarana dan prasarana melalui rapat. Dalam penggunaan sarana dan prasarana tidak ada aturan tertulis. Pemeliharaan sarana dan prasarana melibatkan semua warga madrasah dalam perawatan dan penyimpanan sarana dan prasarana. Pengawasan sarana dan prasarana dilakukan dengan pengecekan langsung pada obyek sarana prasarana yang dimiliki.

\section{Prestasi siswa kelas 4 di MI MA'ARIF NU Kertayasa}

Prestasi belajar merupakan hasil belajar seseorang yang dihasilkan dari proses pembelajaran, salah satunya adalah Guru harus mampu mengelola pembelajaran dari sumber, metode dan strategi pembelajaran dan guru harus mampu menyiapkan media yang tepat untuk pembelajaran yang diajarkan. Selama pembelajaran di MI MA' ARIF NU Kertayasa, guru menggunakan media pembelajaran audiovisual seperti proyektor/LCD dalam beberapa pelajaran. Hal ini sesuai dengan apa yang dikatakan ibu Umriyah:

"Saya menggunakan media proyektor/LCD pada beberapa pembelajaran, ketika saya menggunakan media proyektor membuat siswa semangat 
belajar karena dalam pembelajaran menampilkan sebuah gambar dan suara yang menarik perhatian"

Berdasarkan penjelasan di atas, guru memegang peranan penting dalam proses pembelajaran. Siswa akan merasa nyaman belajar ketika guru menjadi fasilitator dan mediator yang sangat baik yang merupakan bagian dari berhasilnya proses pembelajaran. Hasil belajar akan meningkat karena motivasi dalam diri pelajar ditimbulkan dalam setiap pembelajaran. Hal ini memudahkan siswa dalam menyerap ilmu yang diberikan oleh guru dan dapat menginspirasi mereka dalam bentuk motivasi, Dalam wawancara saya kepada bu Umriyah beliau mengungkapkan:

"Ya, setiap pembelajaran saya akan selalu memberikan motivasi belajar kepada anak-anak agar mereka semangat belajar"

Dari pembahasan di atas dapat disimpulkan bahwa guru adalah sosok yang dikagumi dan diteladani oleh siswa. Oleh karena itu, sangat penting untuk memberikan motivasi, inspirasi dan panutan kepada siswa, karena akan mempengaruhi hasil belajar siswa. Guru memegang peranan penting dalam proses pembelajaran dan kualitas pembelajaran di sekolah sangat ditentukan oleh guru hal ini sesuai dengan Peraturan Menteri Agama (PMA) Nomor 90 Tahun 2013 BAB VI pasal 30.

Hasil pembahasan penelitian dapat disimpulkan bahwa peran guru dalam meningkatkan prestasi siswa telah berjalan dengan baik memberikan motivasi dalam proses belajar, menggunakan media pembelajaran yang ada sesuai dengan RPP menghasilkan prestasi akademik dan non akademik siswa juara lomba sehingga mendapatkan nilai Akreditasi B.

Kepala sekolah memiliki peran penting dalam maningkatan mutu pendidikan di lembaga pendidikan ( Warsiyah,) salah satu manajemen mutu yang sangat penting untuk meningkatakan mutu adalah

\section{Kesimpulan}

Peran manajerial Kepala Sekolah MI MA'ARIF NU berperan untuk membuat dan menyusun perencanaan pengadaan sarana dan prasarana melalui rapat. Dalam penggunaan sarana dan prasarana tidak ada aturan tertulis. Pemeliharaan sarana dan prasarana melibatkan semua warga madrasah dalam perawatan dan penyimpanan sarana dan prasarana. Pengawasan sarana dan prasarana dilakukan dengan pengecekan langsung pada obyek sarana prasarana yang dimiliki. Peran guru dalam meningkatkan prestasi siswa telah berjalan dengan baik memberikan motivasi dalam proses belajar, menggunakan media pembelajaran yang ada sesuai dengan RPP menghasilkan prestasi akademik dan non akademik siswa juara lomba sehingga mendapatkan nilai Akreditasi B. 


\section{Saran}

Pihak Yayasan dapat mengusahakan bantuan sarana dan prasarana dari pemerintah, dan hendaknya kepala madrasah memanfaatkan area-area atau tanah tak tergunakan untuk membuat gudang untuk menyimpan sarana dan prasarana yang sudah tidak terpakai lagi. Dan untuk guru agar dapat menentukan langkah-langkah selanjutnya untuk meningkatkan prestasi belajar siswa dengan melihat cara-cara belajar siswa. 


\section{Daftar Pustaka}

Ahmad, S. (2014). Strategi Pembelajaran. Rajawali Pres, Jakarta

Ananda, R., \& Oda K. B. (2017). Manajemen Sarana dan Prasarana Pendidikan. CV. Widaya Puspita, Medan

Arifin. (2017). Upaya Diri Menjadi Guru Profesional. Alfabeta, Bandung

Arifin. M., \& Barnawi. (2012). Manajemen Sarana dan Prasarana Sekolah. Ar-Ruzz Media, Yogyakarta

Bachri, B. S. (2010). Meyakinkan Validitas Data Melalui Triangulasi pada Penelitian Kualitatif: Jurnal Teknologi Pendidikan. Vol.10 (1). 56

Bafadal, I. (2014). Manajemen Perlengkapan Sekolah Teori dan Aplikasinya. Bumi Aksara, Jakarta

Cucu, S., \& H. (2010). Konsep Strategi Pembelajaran. PT Rafika Aditama, Bandung

Daryanto. (2011). Media Pembelajaran. Satu Nusa, Bandung

Fuad, N., \& Matin. (2016). Manajemen Sarana dan Prasarana Pendidikan: Konsep dan Aplikasinya. Rajawali Pres, Jakarta

Hartini, A. L. (2011). Manajemen Pendidikan. PRESS Sindo, Yogyakarta

Indrawan, I. (2015). Pengantar Manajemen Sarana dan Prasarana Sekolah. Deepublish, Yogyakarta

Minarti, S. (2012) Manajemen Sarana dan Prasarana Pendidikan. Ar-Ruzz Media, Yogyakarta Bandung

Mulyasa, E. (2012). Manajemen Berbasis Madrasah. Remaja Rosda Karya,

Mustari, M. (2015) Manajemen Pendidikan. PT Raja Grafindo, Jakarta

Nurabidin. (2014) Manajemen Sarana dan Prasarana Pendidikan. UM Press, Malang

Raflis K., \& Soetjipto. (2009). Profesi Keguruan. Rineka Cipta, Jakarta

Rusman. (2013). Model-Model Pembelajaran. Raja Grafindo, Jakarta

Saihudin. (2018). Manajemen Institusi Pendidikan. Uwais Inspirasi Indonesia, Ponorogo

Sari, E. (2019). Manajemen Lingkungan Pendidikan. Uwais Press, Jakarta

Sugiyono. (2016) Metode Penelitian Pendidikan: Pendekatan Kuantitatif, Kualitatif, dan $R \mathcal{E} D$. Alfabeta, Bandung

Terry, G., R. (2012) Prinsip-Prinsip Manajemen. Bumi Aksara, Jakarta

Wahyudi. (2012). Kepemimpinan Kepala Sekolah Dalam Organisasi Pembelajaran. Alfabeta, Bandung

Al-Fikri: Jurnal Studi dan Penelitian Pendidikan Islam 
Yusuf, M. (2016). Metode Penelitian: Kuantitatif, Kualitatif, Dan Penelitian Gabungan. KENCANA, Jakarta

Zainiyati, H., \& Salamah. (2017). Pengembangan Media Pembelajaran Berbasis ICT. Kencana, Jakarta 